\title{
Research on the Progress of Microbiological Parametres During the Maturation of Two Kinds of Semi-Hard Cheese
}

\author{
Mirela JIMBOREAN*, Dorin ŢIBULCĂ \\ Department of Food Engineering. University of Agricultural Science and Veterinary Medicine Cluj-Napoca \\ *Corresponding author, e-mail:mirelajimborean2004@yahoo.com
}

Bulletin UASVM Food Science and Technology 71(1) / 2014

ISSN-L 2344-2344; Print ISSN 2344-2344; Electronic ISSN 2344-5300

\begin{abstract}
The microbiological analysis is being done since the moment of production until the end of maturation of two kinds of semi-hard cheese (Olanda and Moeciu).

It was identified the total number of germs using the horizontal method for the list of microorganisms; for the numbering of yeasts and moulds it was used the technique of countering at 25 degrees Celsius; for the detection of coli form bacteria was used the number's method most probably at 30 degrees Celsius; to establish the number of Escherichia coli was used the technique of the probable number; for the numbering of the coagulum-positive staphylococcus the standard stipulates the numbering of the colonies obtained on a solid environment (the environment Baird-Baker), after the aerobic incubation at 35 degrees Celsius or 37 degrees Celsius.
\end{abstract}

\section{INTRODUCTION}

Different sorts of cheese are very complex from the point of view of microbiology. Because of this, the assessment of their general microbiological quality is very hard to be done or sometimes even impossible. This happens mostly because of the action of the micro flora used in their production. The microbiological controls done on cheese usually follow the detection of some pathogenic germs or assess the causes of some faults.

In the conditions of non-compliance of the technological process and the hygienic and sanitary norms, the microbiological contamination leads to the colonization of cheese with a series of zymogen microorganisms (nonspecific micro biota), involved in the alteration (organotrophic, saprophytic microorganisms) or as risk factors for the consumers' health (pathogenic microorganisms and those causing toxins).

\section{MATERIALS AND METHODS}

The tests had been analyzed at different periods of time after the date of production and had been noted as follows:

$\mathbf{P}_{1}$ - the sample at 48 hours from production;

$\mathbf{P}_{2}$ - the sample at 10 days from production;

$\mathbf{P}_{3}$ - the sample at 25 days of ripening;

$\mathbf{P}_{4}$ - the sample at 50 days of ripening;

$\mathbf{P}_{5}$ - the sample in the end of shelf life.

According the regulations in force, the first table contains the microbiological conditions that the analyzed cheese suffered.

\section{RESULTS AND DISCUSSIONS}

The statistical analysis of the evolution of microbiological parameters of cheese - test $t$, (two ways ANOVA) during maturation in the industrial research, is presented in Tables 2 and 3 . 
Table 1. Microbiological normative for chees (Regulation no. 1441/2007)

\begin{tabular}{|c|c|c|}
\hline $\begin{array}{l}\text { Tested microorganisms } \\
\text { (Maximum accepted number/g) }\end{array}$ & $\begin{array}{c}\text { Type of cheese } \\
\begin{array}{l}\text { Fermented hard and semi- } \\
\text { hard cheeses }\end{array}\end{array}$ & Method of analysis \\
\hline Total number of germs & - & SR EN ISO 4833/2005 \\
\hline Coliform bacteria & 10 & SR ISO 4831/2006 \\
\hline Escherichia coli & Abs. & SR ISO 16649/2007 \\
\hline $\begin{array}{c}\text { Salmonella (maximum accepted number / } 25 \\
\text { g) }\end{array}$ & Abs. & SR EN ISO 6579/2006 \\
\hline Staphylococcus coagulazo - positives & 10 & SR EN ISO 6888-1/2005 \\
\hline Total number of yeasts and moulds (cfu/g) & 2000 & SR ISO 7954/2001 \\
\hline Listeria monocytogenes & & SR EN ISO 11290-1/2005 \\
\hline
\end{tabular}

The NTG analysis aerobic mesophylls/ g product has shown that during the maturation process this indicator has constantly increased. At the micromycetes/g product examination it was concluded a rise of their number for all analysed ranges. The bacteriological examination to detect the coli form bacteria in the sorts of cheese subdued maturation, it was discovered their absence in the analysed ranges.

Yeasts and toxigenic moulds which contaminate cheese may represent a real treat for man's health, as they can multiply and produce aflatoxins. In order to avoid the production of mycotoxins in contaminated cheese, some researchers recommend the addition of different inhibitory substances in these products.

Yeasts which stand for a low $\mathrm{pH}$ and a relatively high concentration of sodic chloride, form at the surface of some sorts of cheese a first viscid stratum; they use lactic acid, they fuse casein's degradation and cause the local rise of $\mathrm{pH}$; then the micrococcusi and bacteria develop into canes. Among the last ones we find species which produce a red pigment, the core representatives are Bacterium linens and Bacterium erythrogenes; they are proteolytic, with an optimal pH between 6 and 9 and are active at high salt concentrations. (DAN Valentina, 2000).

The results which refer to the presence of $E$. coli bacteria biotype I in the sorts of cheese which underwent maturation, indicates its absence in the analysed ranges.

The pasteurization of milk destroys pathogenic bacteria, but L. monocytogenes and E. coli 0157:H17 can survive and contaminate the final product. The survival depends on a few factors: the initial level of contamination, the temperature of pasteurization, the tolerance at acids and salt of microorganisms, the competitive micro flora, the composition of cheese and the conditions in which they have been obtained. Fetta cheese can favour the growth and survival of $L$. monocytogenes for 90 days of depositing at 4 degrees Celsius when the $\mathrm{pH}$ is under the value 4,3 (T. BINTSIS, P. PAPADEMAS, 2002).

Some sorts of cheese, especially those with soft and semi-hard paste, can be contaminated with E. coli and may cause food poisoning. Nowadays, in most of the countries, research on coli form bacteria in pasteurized milk is being done regularly. It is ascertained that pasteurized milk in which phosphatase is inactive doesn't contain coli form bacteria. That is why it is necessary to take measures to avoid the recontamination of pasteurized milk.

The examinations for the detection of Salmonella, Listeria monocytogenes and coagulum-positive staphylococcus, the results were negative at all the tests.

Many sorts of cheese were incriminated in the production of food poisoning, although they were made of pasteurized milk. This shows a recontamination of milk after the pasteurization process or of the products during the production. In cottage cheese with a $\mathrm{pH}$ of 4,1 ....4,4 S. paratyphi, S. typhimurium, S. cholerae suis, $S$. enteritidis and $S$. dublin die after 3...7 days (BĂRZOI D. and APOSTU S., 2002).

BĂRZOI, D. and APOSTU S., 2002, showed that cheese are very complex microbiologically speaking. Because of this, the valuation of their general microbiological quality is very hard to be done or sometimes impossible. To this contributes largely the intervention of the micro flora in the technology used for their manufacture. 


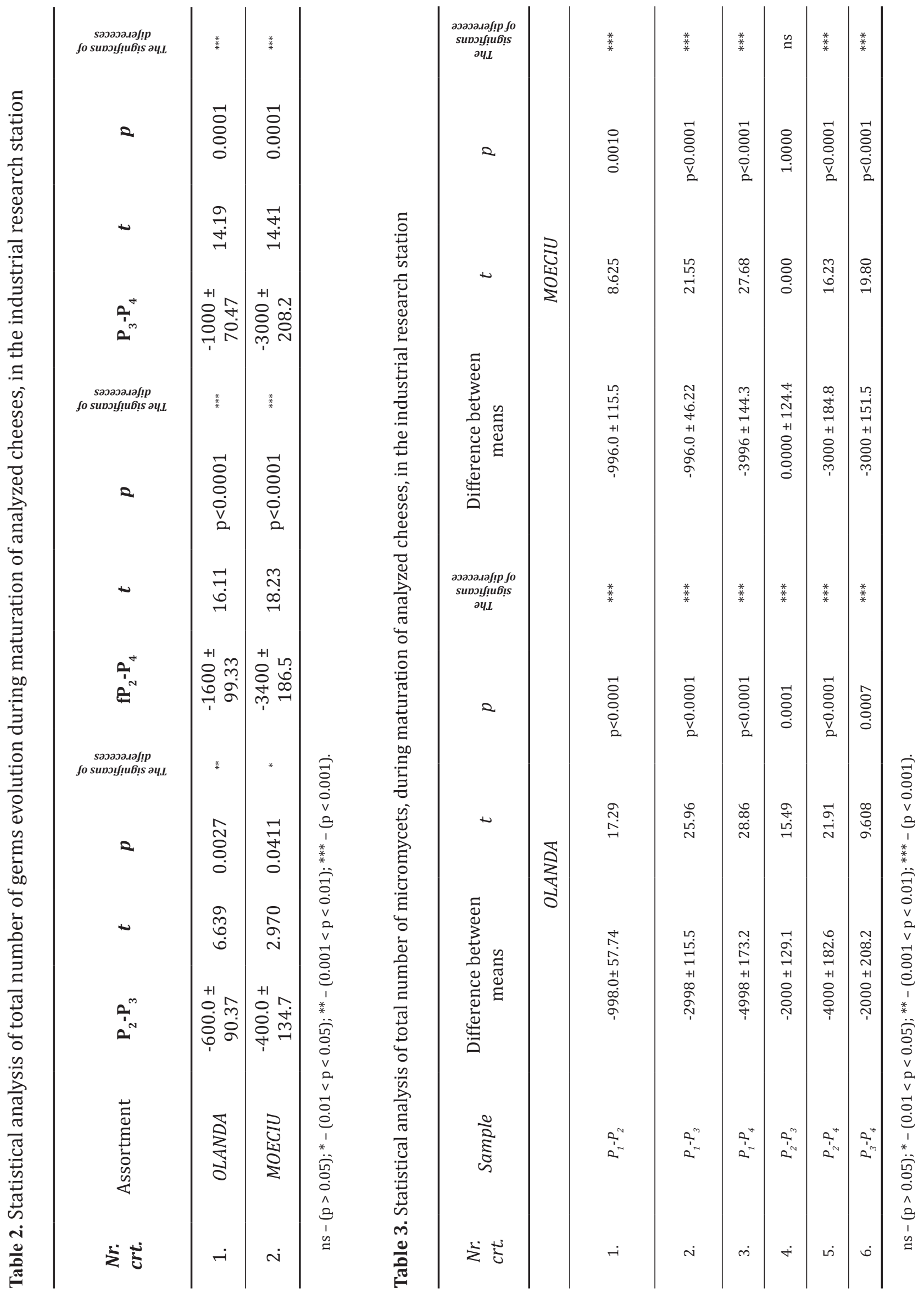


There are trials to find some data which can be used to assess the general microbiological quality of cheese, as to ascertain the link between the lactic micro flora and another micro flora. In the case of a cheese which suffered a normal maturation has to be at least 100:1. When the link is 100:5 it means that there are some errors in the technological process. In order to establish this link one has to identify in parallel the total number of germs on yeast-lactose-agar extract of agar.

As a whole, ferment cheese doesn't raise microbiological problems in point of innocuity. During the maturation process, for most of the cheese ranges the pathogenic micro-organisms probably present are destroyed thanks to the rivalry of the lactic micro flora and the $\mathrm{pH}$ conditions from the products. This destruction is faster if the ageing temperature is higher (Emmental cheese), when for the cheese with a lower temperature of ageing (Cheddar, Trapist, Tilsit and other) the micro-organisms resist for a longer period of time (BĂRZOI D. and APOSTU S., 2002).

\section{CONCLUSIONS}

It is obvious that the rate of survival of pathogenically bacteria in cheese depends on water's activity, $\mathrm{pH}$, salt content, maturation temperature.

The total number of germs was 0 when both sorts of cheese were obtained, afterwards they begin to multiply and show significant statistically differences (**) between the trials P1-P2 in the case of Olanda cheese and significant differences in Moeciu. For both sorts of cheese, between P2P4 and P3-P4 the differences and statistically significant $\left.{ }^{* * *}\right)$ on the NTG evolution during the maturation of the analyzed cheese.

The statistical analysis of the evolution of the total number of micromycets the maturation of the analysed cheese has emphasized some very significant differences $\left(^{* * *}\right)$ between all the trials in Olanda cheese case. For Moeciu cheese, except the trials P2-P3 where the difference was statistically irrelevant (ns), in all the other trials very significant differences have been registered $(* * *)$, as regards the number of yeasts and moulds/g.

The examination of the micromycetes/g product revealed an increase of their number in all sorts of cheese analysed. The values of this indicator were at some trials over the limits accepted by Reg. 1441/2007. For Olanda cheese, 25 days after the date of fabrication the total number of germs was 1.5 times as compared to the accepted limit and at the end of maturation (50 days after the date of manufacture) it was 2.5 times. For Moeciu cheese, at the end of maturation the limit was exceeded 2.5 times as compared to the requirements of the regulation. In these respects, it can be concluded that there have been contaminations with yeasts and moulds both during the technological process and while the maturation of cheese.

The exams for the detection of Salmonella, Listeria monocytogenes and Staphylococcus curdledpositive, the results were negative in all the trials examined. In terms of Listeria monocytogenes, milk is considered one of the vehicles of the germ from animals to man, although the way of oral infection hasn't been until now sufficiently demonstrated. The main danger of contamination of milk and diary products with staphylococci refers to the development of some strains of an enterotoxin causing at man an acute gastroenteritis.

\section{REFERENCES}

1. Bărzoi, D. and Apostu, S. (2002). Microbiology of food, Ed. Risoprint, Cluj-Napoca.

2. Bintsis, T. and Papademas, P. (2002). Microbiological quality of white-brined cheese: a review, Int. Journal of Dairy Technology, 55 (3): 113 - 119.

3. Dan, V. (2000). Microbiology of food, vol. II, Ed. Alma, Galaţi.

4. *** Regulation (CE) no. 1441/(2007), Microbiological standards for foods. 